\title{
Breast Augmentation in Bangladesh with Silicone Gel Implants -A Short Term Experience
}

ANAM S ${ }^{1}$, KHONDOKER MS², RAHMAN SA ${ }^{3}$

\begin{abstract}
Background:. The primary breast augmentation surgery was not popular for a long time in Bangladesh but with the gradual economic and educational development, as well as availability of silicone gel implant and skilled surgeons, the demand, popularity and acceptance of this surgery is increasing.
\end{abstract}

Objective:This study was done to assess the efficacy of the implants in 30 consecutive patients who presented for breast augmentation .

Methods:Data were prospectively collected for all patients who underwent bilateral breast augmentation between July 201 I to November 2012. Breast augmentation was performed by placing textured, round, silicone gel implant in subglandular position via inframammary approach. The 30 patients included in this series were analyzed according to demographic details, preoperative findings, postoperative patient and observer satisfaction scores, and complications. Standard pictures were taken before surgery and during follow-up visits over 6 month; standardised objective measurements of breast and chest were also taken. The test statistics used to analyze the data were descriptive statistics and repeated measure ANOVA .A Visual Analogue Scale (VAS) was used to evaluate the subjects' global impression of clinical improvement and one independent observer visually reviewed pre and postoperative result to grade aesthetic results

Results: Observers evaluation by predefined criteria (volume, shape, consistency, inframammry fold and scar) rated $60 \%$ of patients with excellent outcome, $30 \%$ good, $10 \%$ fair and none had poor score. A significant percentage (63.3\%) of the 30 patients rated their satisfaction as very good and nine (30\%) patient rated as good. None of the patients responded the result as poor or as very poor. No serious complications such as implant malposition or significant capsular contracture were observed

Conclusions: We conclude that round textured cohesive gel implants provide excellent results, are well accepted by patients and most short-term postoperative adverse effects following cosmetic implantation are clinically insignificant and do not require treatment.

Keywords: Augmentation Mammoplasty, Silicone gel implants

\section{Background}

The role of augmentation mammaplasty is, obviously to increase the volume, size, profile and projection of breast along with improvement in breast symmetry, shape and nipple position. ${ }^{1,2}$

Woman choose to undergo breast augmentation because they are naturally small busted, have developed excessive volume loss with pregnancy, lactation or weight loss, have developed breast sagging, have an asymmetry in breast size or shape or simply want to enhance their existing breast

1. Dr.Salma Anam, Student, MS (Thesis Part), Burn, Plastic and Reconstructive Surgery, DMCH, Dhaka.

2. Prof. Md. Sazzad Khondokar, Prof. of Burn, Plastic and Reconstructive Surgery, DMCH, Dhaka.

3. Dr.Shariff Asfia Rahman, Student, MS (Thesis Part), Burn, Plastic and Reconstructive Surgery,DMCH, Dhaka.

Address of Correspondence: Dr. Salma Anam, Department of Burn, Plastic and Reconstructive Surgery, Dhaka medical College Hospital,Dhaka.Email: salma_anam@yahoo.com contour. ${ }^{1}$ Woman with smaller than normal breast usually have negative body image and seeks correction through augmentation mammoplasty. A beautiful breast must look natural and in proportion with rest of the body. Therefore the conceptual goal of breast augmentation is to have a soft, full, natural looking, non-ptotic, well positioned mobile breast that respond to gravity and postural changes along with fewest possible complications and also to fulfil patients desire. ${ }^{4}$ Woman who are concerned about the size of their breast, seek an improved appearance with breast augmentation to conform to their own body image. This in general enhances their self-image, increase self-assurance and establish better interpersonal relationship.

Silicone gel breast implants were first introduced for the use of breast augmentation by Dow Corning in 1962 following the original designs of Dr. Cronin and Gerow. ${ }^{3}$ These implants have gone from a 1992 moratorium to approval in 2006, with many developments in manufacturing and usage in between and currently dominate the worldwide breast implant market. 
Silicone gel implant commercially available today is refined and safer devices than their predecessors. Large bodies of data now support the safety of breast implants in general, with the main safety concerns being the potential for local complications and the need for secondary surgeries With the advances in implant technology involving both enhanced texturing, cohesiveness more consistent aesthetic breast form can be achieved. In general silicone gel filled implants tends to feel more natural, look better subgladularly compare with saline implant show less rippling and better suited for patient with minor ptosis. The consistency of the gel creates softer, more natural peripheral breast contour and overall softer feel to the breast. The surgeon can use specific measurements of breast width, and projection to custom select an implant specific to each breast. Patient need to be carefully selected and oriented and at the same time proper evaluation of the case and choice of the most adequate implant and plane of location are essential to obtain a consistently excellent result. ${ }^{3}$

Augmentation mammaplasty has become one of the most popular aesthetic procedures in the world. It is estimated that more than $1 \%$ of the adult female population in the United States (between 1 and 2 million) has undergone breast augmentation using implant. About $80 \%$ of implants are placed for cosmetic purposes and $20 \%$ for reconstructive reasons. ${ }^{14}$ With rapid economic development in Southeast Asia, breast augmentation and other cosmetic surgeries are increasingly performed. Due to scepticism and ignorance this cosmetic surgery was not popular for a long time in Bangladesh but with economic growth and educational development, as well as availability of silicone gel implant and skilled surgeons, the demand, popularity and acceptance of this surgery is gradually increasing. In spite of our conservative culture and religious taboos woman in Bangladesh are becoming interested in this procedure.

\section{Methods}

\section{Sample Population}

This prospective observational study analyzed 30 patients undergoing primary augmentation mammaplasty between July 2011 to November 2012 in different private hospitals as well as in Plastic Surgery Department, DMCH, and Dhaka. All female patients aged 18 years or above with hypomastia and desiring for cosmetic breast augmentation were considered as the study population. The exclusion criteria specified previously performed breast surgery and simultaneously conducted mastopexy, medical history precluding suitability for surgery (eg, advanced fibrocystic disease or inadequate breast tissue), pregnancy or breastfeeding, any condition that might constitute an unduly high surgical risk, and psychological characteristics that might be incompatible with the surgical procedure or the implant.

\section{Data Recording}

Preoperative data. In all cases, the following were recorded: patient demographic information, breast cup size, breast width, presence of ptosis (grade-1), midline-to-nipple distance, areola-to-inframammary fold (IMF) distance, suprasternal notch-to-nipple distance. Traditional system of cup size measurement was utilized in present study.

Operative data. The volume of implants placed was recorded in each case. Implant selections were made based on data from measurements, including reasonable patient wishes for size outcome. Large-volume augmentation with devices that exceeded the breast base diameter was avoided.

Postoperative data. Data regarding the aesthetic effect of implantation on the breast included- correction of ptosis and postoperative cup size increase. Early complications were recorded, including hematoma, wound infection, and seroma formation. Longer-term outcomes such as scar quality, capsular contracture (CC), nipple sensation were recorded at least six months postoperatively. The results were evaluated and compared 1. 3 and 6 months after augmentation using the patients' own assessments (a rating of $0-10$ points) and scoring by observer (using five subscales of the modified Garbay system). Each patient received an assessment sheet to record her postoperative satisfaction with clinical improvement using a visual analogue scale (VAS), indicating satisfaction with volume, symmetry, shape, scar \&consistency. Breast symmetry, shape, inframmary fold, consistency and scar quality were subjectively evaluated during follow-up visits following surgery by an observer. The effectiveness evaluation included changes in bra cup size from pre- to post surgery, subject and observer satisfaction with the implants.

\section{Surgical Method}

Preoperative planning. Implant base diameter selected was slightly $(0.5 \mathrm{~cm})$ less wide than the existing breast width. Implant projection was selected by subtracting the preoperative mammary projection from the projection desired by the patient. After considering these two implant variable, implant volume was determined from the manufacturer's published data charts. By this means, an approximate volume and projection of the implant was determined preoperatively. In this patient series, only round, textured, cohesive silicone gel implants were placed in subglandular pocket by giving inframammary incision. 
Operative technique. All patients are counselled and informed about the risk and benefit of the procedure. Preoperative markings are done with patients standing in normal anatomical position. The boundaries of implant pocket are delineated. With patient under general anaesthesia access in all cases was via an inframammary incision no more than 5 $\mathrm{cm}$ in length, Skin and subcutaneous tissue incised. After sharp dissection on top of pectoralis major fascia, subglandular pocket preparation is completed bluntly using finger dissection according to preoperative marking. Preoperatively selected silicone gel, textured, round implant of definite volume is inserted into the pocket followed by meticulous haemostasis. One drain was inserted via a stab incision placed laterally to each breast. Closure was achieved in 3 layers- fascia and dermal layer with 3-0 Vicry and skin with 5-0 prolene sutures. Surgical dressings were applied to the wounds and drain sites.

Oral antibiotics were continued for one week postoperatively. Drains were removed the following day and stitches removed after one week. Patients were advised to avoid physical exercise for 3 weeks. Follow up care consists of outpatient visit on $1^{\text {st }}, 4^{\text {th }}, 12$ th and 24 th week.

\section{References}

\section{Preoperative Data.}

Demographic data revealed that the mean age of patients was 31.8 years (range, 20-40 years). Majority of women to be married $(76.6 \%)$, house wife $(43.2 \%)$, and were graduate (73.2\%). Maximum number of subjects was candidate for cosmetic breast augmentation (46.6\%).Ptosis grade - 1 was present in $8(53 \%)$ cases. The most common pre-augmentation cup size was $\mathrm{A}$, with a range from $\mathrm{AA}$ to $\mathrm{C}$

\section{Operative Data}

The size of implant placed in primary augmentation ranged from 180 - $380 \mathrm{cc}$ and in $43.3 \%$ cases implant volume used were between $280-300 \mathrm{cc}$

\section{Postoperative Data}

Follow-up ranged from 1 week to 6 months. Postoperative assessment showed an overall increase in breast volume by an average of 2.96 cup sizes. Postoperatively majority of augmented subjects had increase in 3 cup size $(76.7 \%)$ followed by 2 cup size increase in $(13.3 \%)$ and 4 cup size increase in $(10 \%)$ cases. None of the patient had single cup size increase. The post implantation increase in cup size was significant and met the patients' desire. Breast ptosis was corrected in 7 patients $(96.7 \%)$ out of 8 by placing implant but only one $(3.3 \%)$ patient still had ptosis after augmentation.

The data collected by physicians during visits showed that at 1 st week postoperatively the most common complications for augmentation subjects were breast pain (26.7\%)and altered nipple sensory change noted in 11(16.7\%) of the 30 primary augmentation cases . In three cases, this change was unilateral, and in eight cases, it was bilateral. Early complications included 3 cases (10\%) of hematoma requiring drainage, five cases $(16.7 \%)$ of small seroma not requiring surgery, one $(3.33 \%)$ minor postoperative wound infections requiring antibiotic treatment. Over one-third (36.7\%) of surgery-related minor complications (like hematoma, seroma, infection, breast pain and altered NAC sensation) developed in the $1^{\text {st }}$ week which then gradually decreased and only 2 cases $(6.7 \%)$ of altered NAC sensation and 2 cases $(6.7 \%)$ of breast pain at month 6 . Implant palpability/visibility was experienced by two patients (6.7\%) and two patients $(6.7 \%)$ had slight hypertrophic scarring at 6 month.

Subjective patient assessment at least six months postoperatively revealed a high level of patient satisfaction. Patients own appraisal of satisfaction with overall outcome judged on a scale of 1 to 10 , where the patients were asked to score by their own regarding volume, symmetry, shape, scar \&consistency and the data was recorded by a non-biased third person not related to this study; A large number of patients marked their satisfaction as very good $(19,63.3 \%)$, $\operatorname{good}(9,30 \%) \&$ satisfactory $(2,6.6 \%)$. Whereas, none of the patients responded the result as poor or as very poor.

Observers evaluation (subjective) by predefined criteria (volume, shape, consistency, inframammry fold and scar) rated $60 \%$ of patients with excellent outcome, $30 \%$ good, $10 \%$ fair and none had poor score

The current study is a short term study with small population size. Preliminary safety and effectiveness data from this study indicate that the use of the silicone gel implants yields no capsular contracture, no rupture, no displacement, no revision rates, as well as decreased complication rates and high satisfaction rates. Subject satisfaction with implants was from very good to good in $93.3 \%$ cases. Observer evaluation was excellent to good in $90 \%$ cases. Overall consensus was that there was visual improvement of the breast when compared with the preoperative status..

Majority of breast ptosis were corrected (96.7\%) and 76.7\% patient had 3 cup size increase after augmentation. Despite the prolonged litigation and settlement of lawsuits concerning silicone breast implants and their possible association with life killing complication, there has been resurgence in the frequency of breast augmentation. It has ultimately been shown that there is no link between silicone gel implant and life threatening systemic illness. 
Table V

Indications for breast augmentation

\begin{tabular}{lcc}
\hline Indication & Frequency & Percent \\
\hline Cosmetic augmentation only & 14 & 46.6 \\
Augmentation with breast ptosis & 8 & 26.6 \\
$\begin{array}{l}\text { Augmentation with post } \\
\text { lactation involution }\end{array}$ & 6 & 20.0 \\
$\begin{array}{l}\text { Augmentation with congenital } \\
\text { hypomastia }\end{array}$ & 2 & 6.8 \\
\hline Total & 30 & 100.0 \\
\hline
\end{tabular}

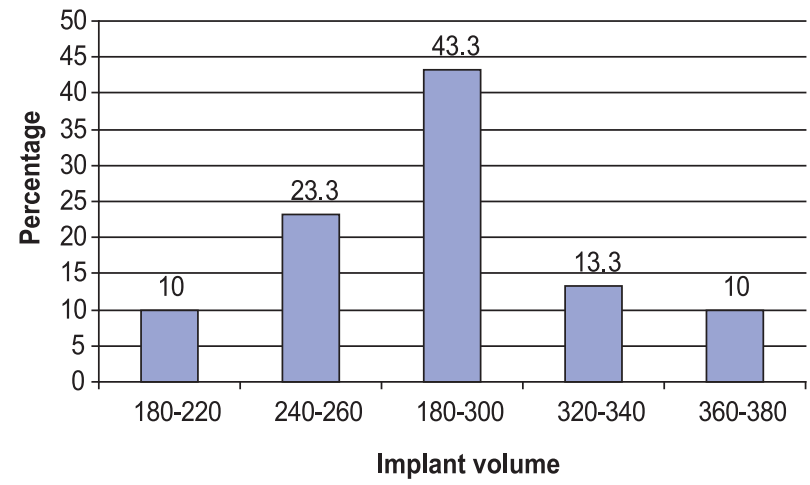

Fig.-1. Implant Volume

Table VI

Preoperative cup size

\begin{tabular}{lcc}
\hline Cup size & Frequency & Percent \\
\hline AA & 6 & 20.0 \\
A & 20 & 66.7 \\
B & 3 & 10.0 \\
C & 1 & 3.3 \\
\hline Total & 30 & 100.0 \\
\hline
\end{tabular}

Table VII

Post-operative Increase in Cup size

\begin{tabular}{lcc}
\hline Increase in Cup size & Frequency & Percent \\
\hline One Cup size increase & 0 & 0.0 \\
Two Cup size increase & 4 & 13.3 \\
Three Cup size increase & 23 & 76.7 \\
Four Cup size increase & 3 & 10.0 \\
\hline Total & 30 & 100.0 \\
\hline
\end{tabular}

Table VIII

Patients own appraisal of satisfaction

\begin{tabular}{lcc}
\hline Satisfaction Score & Frequency & Percent \\
\hline Very Good (9-10) & 19 & 63.3 \\
Good (7-8) & 9 & 30.0 \\
Satisfactory (5-6) & 2 & 6.7 \\
Poor (3-4) & 0 & 0.0 \\
Very Poor (0-2) & 0 & 0.0 \\
\hline Total & 30 & 100.0 \\
\hline
\end{tabular}

Table IX

Evaluation of outcome by observer $(n=30)$

\begin{tabular}{lcc}
\hline Evaluation (score) & Frequency & Percentage \\
\hline Excellent $(10-9)$ & 18 & 60 \\
Good $(8-7)$ & 9 & 30 \\
Fair $(6-5)$ & 3 & 10 \\
Poor $(4-1)$ & 0 & 0 \\
\hline Total & 30 & 100 \\
\hline
\end{tabular}

Table X

Distribution of patients by complications encountered $(n=30)$

\begin{tabular}{lcccc}
\hline Complications & \multicolumn{4}{c}{ Follow up period } \\
& Week 1 & Month 1 & Month 3 & Month 6 \\
& $\mathrm{n}(\%)$ & $\mathrm{n}(\%)$ & $\mathrm{n}(\%)$ & $\mathrm{n}(\%)$ \\
\hline Surgery related & $11(36.7)$ & $8(26.7)$ & $7(23.3)$ & $4(13.3)$ \\
Hematoma & $3(10.0)$ & $0(0.0)$ & $0(0.0)$ & $0(0.0)$ \\
Seroma & $5(16.7)$ & $0(0.0)$ & $0(0.0)$ & $0(0.0)$ \\
Infection & $1(3.3)$ & $0(0.0)$ & $0(0.0)$ & $0(0.0)$ \\
Breast pain & $8(26.7)$ & $8(26.7)$ & $5(16.7)$ & $2(6.7)$ \\
Altered NAC & $11(36.7)$ & $7(23.3)$ & $3(10.0)$ & $2(6.7)$ \\
Implant related & $0(0.0)$ & $4(13.3)$ & $6(20.0)$ & $4(13.3)$ \\
Implant visibility & $0(0.0)$ & $4(13.3)$ & $4(13.3)$ & $2(6.7)$ \\
Implant palpability & $0(0.0)$ & $4(13.3)$ & $4(13.3)$ & $2(6.7)$ \\
Hypertrophic scar & $0(0.0)$ & $0(0.0)$ & $2(6.7)$ & $2(6.7)$ \\
\hline
\end{tabular}




\section{Discussion}

Analysis of demographic data in our study revealed that the patient's age varied from 20 years to 40 years, with mean age $31.8 \pm 5.1$ years. Majority of women were married (76.6\%). Occupational distribution showed most of the women to be house wife (43.2\%), followed by professional (33.3\%). Most of the subjects were graduate $(73.2 \%)$ and attended college (16.7\%). These demographic profiles reflect that women in our study group were educated, financially solvent and married. Subject compliance with the follow-up schedule was $100 \%$.A prospective, nonrandomized study ${ }^{5}$ provided 3 -year follow-up \& demographic data revealed that median age was 36 years for augmentation subjects, most subjects were Caucasian, married, and attended college. Subject compliance with the follow-up schedule was excellent through the first 3 years of the study completed. Another multicentre clinical study 6 in patients undergoing augmentation reported that the median subject age at the time of surgery was 38 years, the majority of subjects were married, and the most commonly reported household income exceeded $\$ 80,000$. Majority of study subjects had completed some college education, with $43 \%$ holding at least a bachelor degree and more than $8 \%$ having completed postgraduate level education.

The above result was somewhat similar to the demographic profile of the current study with higher median age. Due to the social, cultural, financial and religious difference, the women of our society usually do not come for augmentation after the age of 40 years, whereas in the western world older age group are equally concerned about their body image and interested for the procedure. Regarding the financial status, our women can usually afford low cost implant unlike the western women who are more solvent and independent financially thus can avail high cost, more modern implant.

In this study the most frequently used size of the textured round implants positioned in the breast were $280-300 \mathrm{cc}$. (mean $284.6 \pm 47.1 \mathrm{cc}$ ) A study with Contour Profile Gel implant ${ }^{11}$ the volume of the "cosmetic" implants ranged from $215 \mathrm{ml}$ to $355 \mathrm{ml}$, with $280 \mathrm{ml}$ being the most frequently used size. Other studies also used similar range of implantsbetween $280 \mathrm{cc}$ to $320 \mathrm{cc}$ \& 190 to $475 \mathrm{cc}$, with a median of $280 \mathrm{cc}^{7}$.

In our study preoperatively only 8 patients $(26.7 \%)$ had grade-1 ptosis which was corrected in 7 patients $(96.7 \%)$ after augmentation. A study done in Brazil ${ }^{8}$ also showed reduction of breast ptosis present in $53 \%$ of cases (Grade 1, $40.5 \%$; Grade 2, 12.5\%). Thus in the current study, it is evident that breast ptosis was significantly corrected using silicone gel implant in comparison to the study done in Brazil.

If we consider the preoperative cup size of the subjects in this study, the majority $20(66.7 \%)$ had cup size A. Postoperatively majority of augmented subjects had increase in 3 cup size (76.7\%) followed by 2 cup size increase in (13.3\%) and 4 cup size increase in $(10 \%)$ cases. A study ${ }^{8}$ on 200 patients reported the most common pre augmentation cup size was A. Postoperative assessment showed an overall increase in breast volume by an average of 2.6 cup sizes. A nonrandomized study ${ }^{5}$ provided 3-year follow-up found that a majority of subjects (53 percent) had an increase of two cup sizes, and the second most common outcome was an increase of one cup size ( 38 percent).Scott et $\mathrm{al}^{9}$ in a study showed increase in the size was either one cup size (41 percent) or two cup sizes (45 percent).

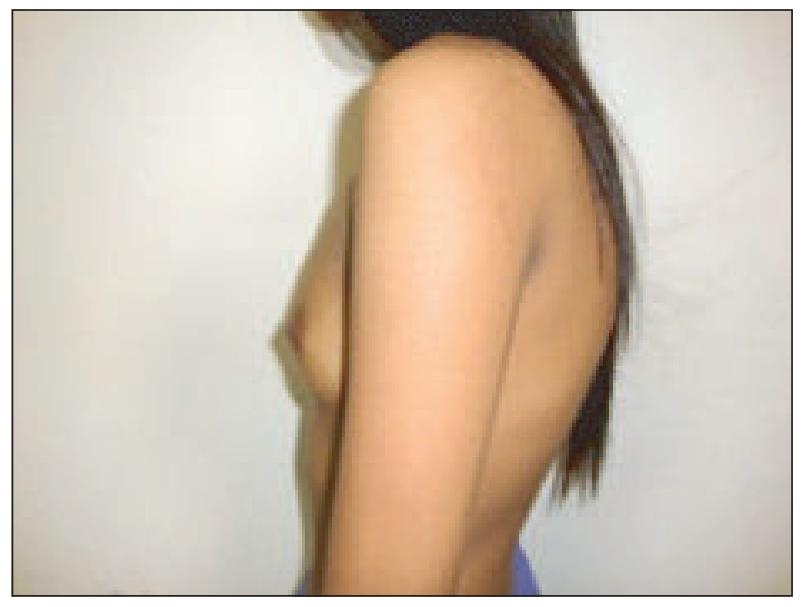

Pre-operative left lateral view(B)

Pre-operative right lateral view $(A)$

Fig.-2. (A,B) A 23 years old lady who presented for breast augmentation. 


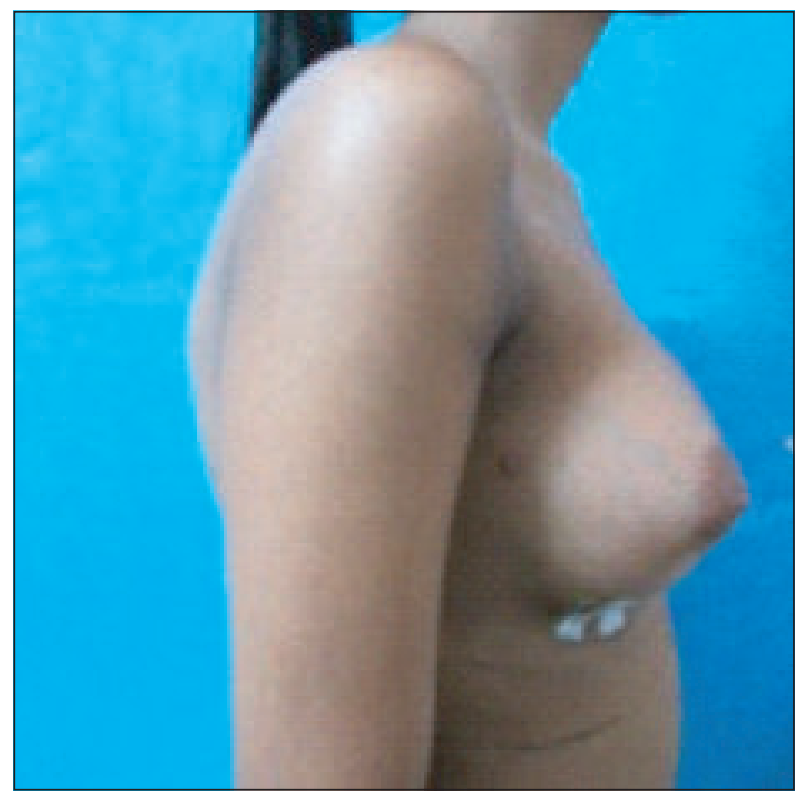

Post-operarive right lateral view (C)

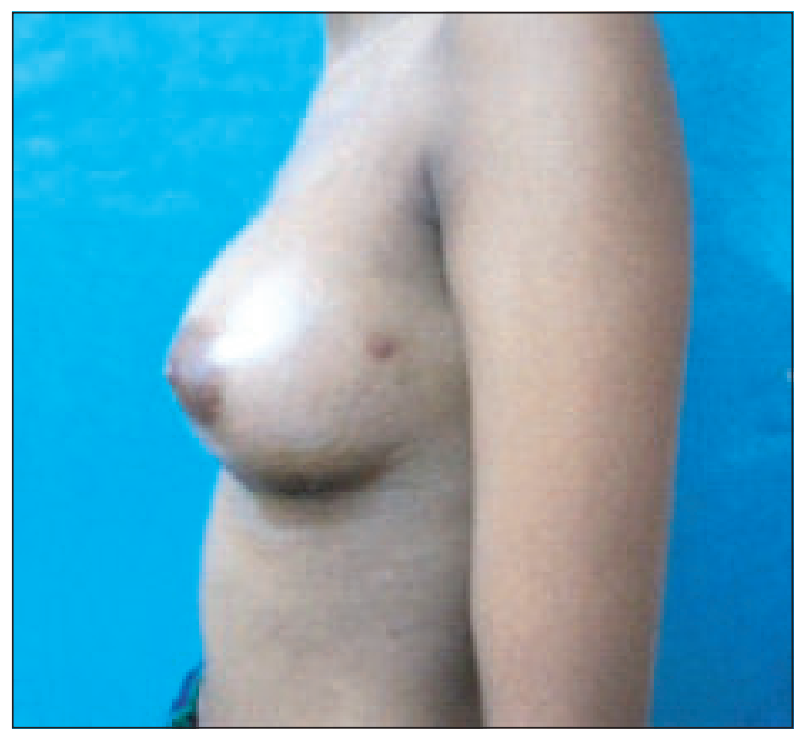

Post-operative left lateral view (D)

Fig.-2: (C,D ) post-operative pictures after insertion of 260 cc of implant.

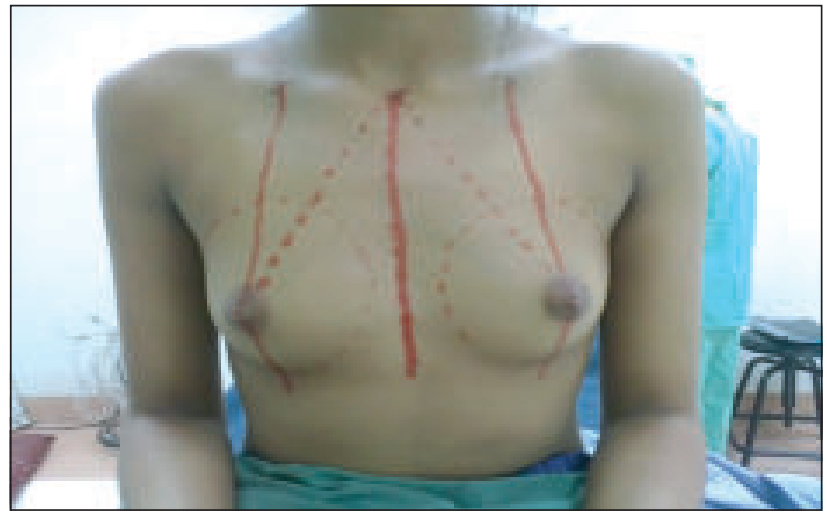

(A) Preoperative Markings

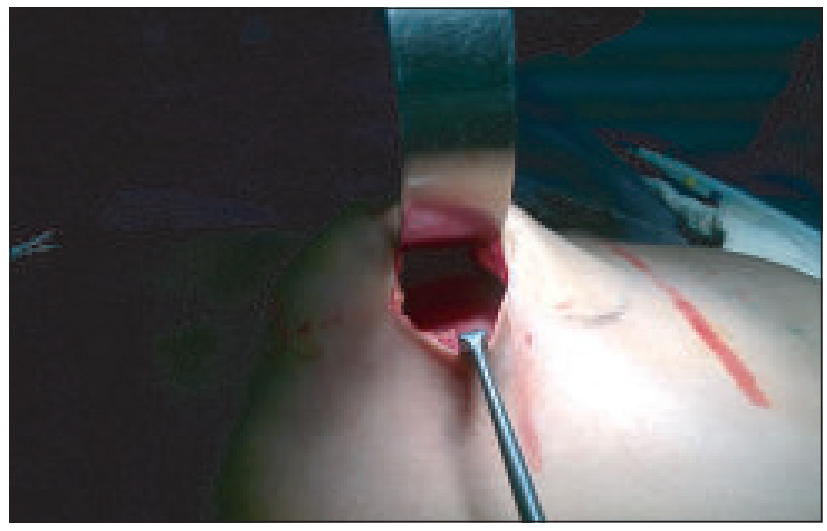

(C) Subglandular pocket for placement of implant created

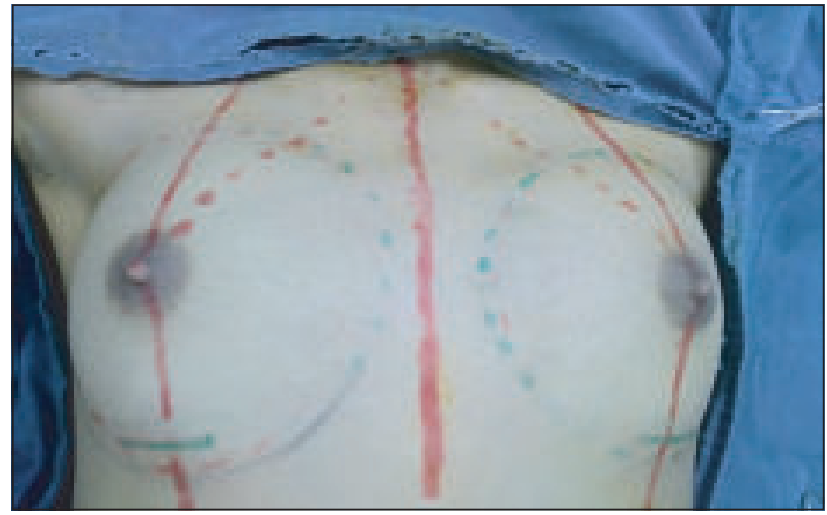

(B) Inframammary Incision Marking

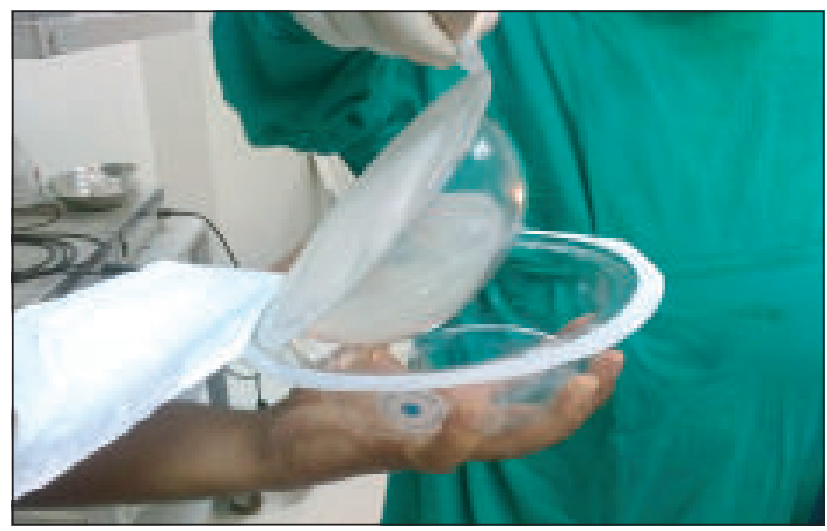

(D) Implant taken out of sealed container

Fig.-3: A-D Operative picture of subglandular implant placement 


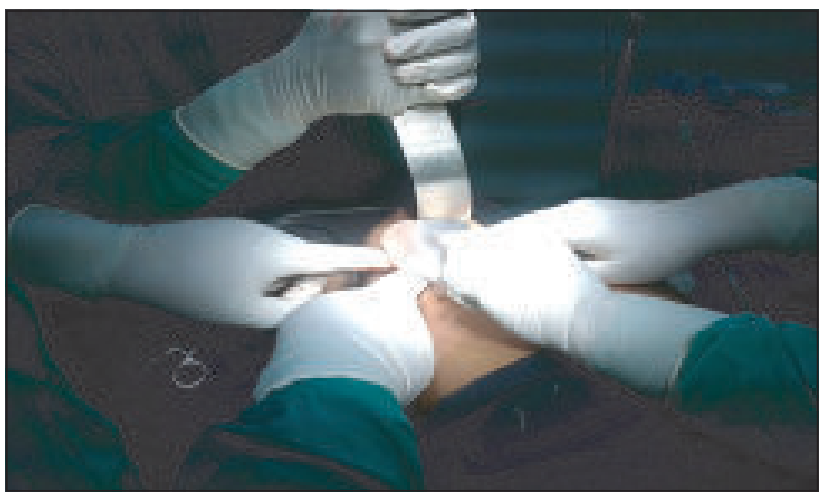

(E) Insertion of the implant in the subglandular pocket

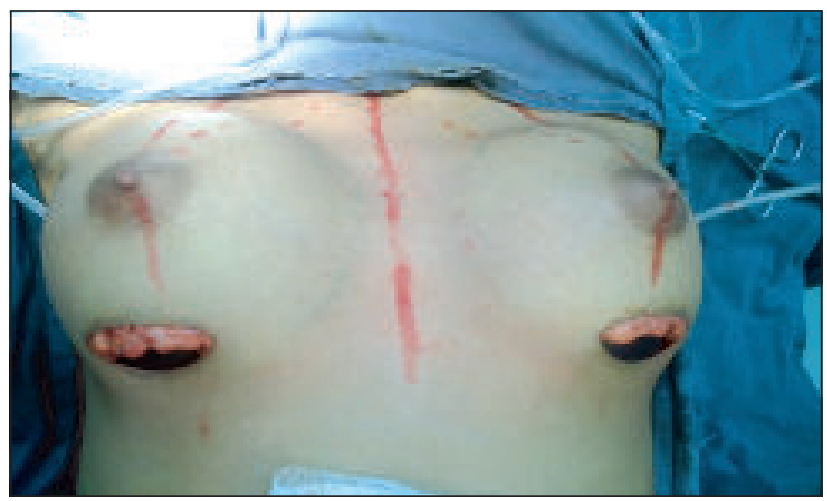

(G) Implant with drain in situ

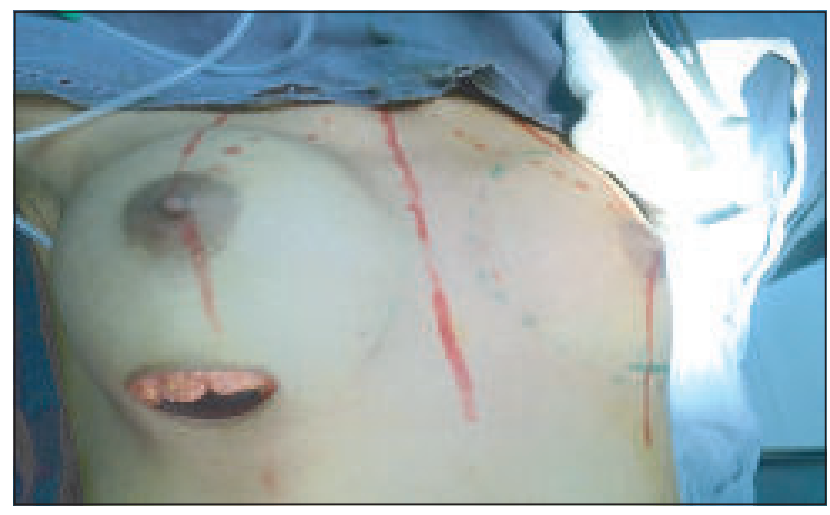

(F) Implant in the right breast

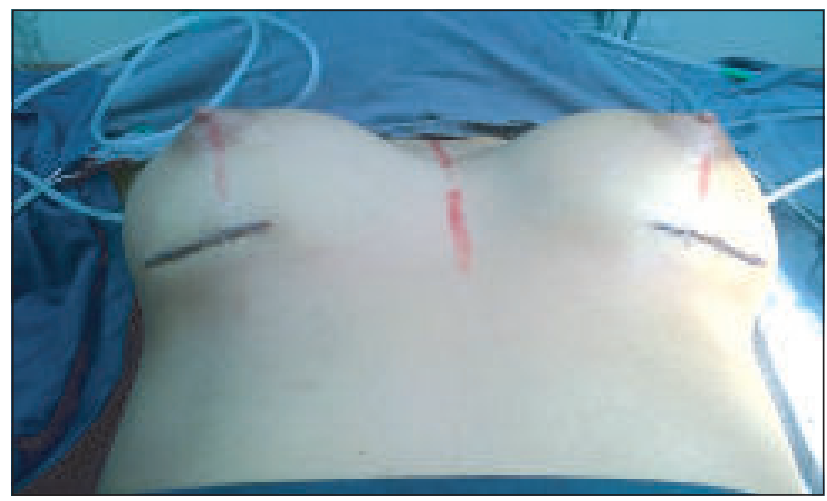

(H) Inframammary skin incision closed

Fig.-3: E-H Operative picture of subglandular implant placement

Most of the studies including our study reported significant increase in cup size after implantation but our study gained more increase in cup size. The reason may be due to insertion of larger volume of implant subglandularly.Furthermore Asian patients have special characteristics that need to be taken into consideration when performing breast augmentation. Asian women are usually short and slim with a low body mass index and small breast compared with Westerners and African Americans. Most women consider C-cup breasts as the ideal size when they are contemplating undergoing augmentation mammaplasty. ${ }^{10}$

In this study the observer graded the aesthetic outcome as excellent in $60 \%$ cases, good in $30 \%$ and fair in $10 \%$ subjects at 6 month. No patient scored poor result. Aesthetic judgement revealed observer's satisfaction with the breast appearance by giving excellent to fair score at the end point of the study. A study ${ }^{11}$ with contour profile gel implant showed $85 \%$ of the breasts were rated as soft. Current study reported soft consistency in $76.7 \%$ at the 6 month follow up. Results were nearly similar between both the studies.

Currently, in the more competitive health care area, patient satisfaction has become an issue of considerable interest.
Breast appearance was subjectively evaluated by the patients during follow-up after surgery. During the first review, all patients were satisfied with the shape but 80 percent thought the implants were too big. In the one-month review, 40 percent of patients still thought the implants were big although they liked the shape. At 6 month review, they reported satisfaction with size and shape and consistency. The women who had experienced detectable complications, i.e., visible or palpable implant conditions and hypertrophic scar were less satisfied than the women who had undergone complications leaving no visible or palpable sequelae.The most compelling finding was that 97 percent patient stated an overall feeling that their breast implantation had been advantageous and subject satisfaction remained high during 6 months after implantation. According to the VAS, good-tovery good patient satisfaction was observed in $93.3 \%$ cases.In our series, none of these patients requested revision surgery.Similar result was seen in a survey done in Brazil ${ }^{12}$ on their experience with PERTHESE silicone breast implants showed over $97 \%$ of patients were satisfied with the surgery results, with $79.6 \%$ of patients rating the surgery results as excellent. Less than $1 \%$ patients were not satisfied with the surgery results. 
The overall assessment of breast aesthetics by the observer and patient yielded comparable results with high degree of satisfaction. Other different studies ${ }^{8,13}$ showed patients and observer satisfaction with breast augmentation was over 90\%. Results were similar with our study.

In the current study early experience shows that silicone gel implants are well accepted by the patients, without any serious aesthetic complications as malposition or capsular contracture. None of our patients experienced any capsular contracture during the short study period. This is in accordance with the findings of Bogetti et $\mathrm{al}^{11}$ in a small study of sub glandular breast augmentation with soft cohesive silicone gel implants. It has been hypothesized that this may be attributable to the insignificant silicone gel bleed of cohesive gel implants. For instance Heden et al implanted 1676 anatomic cohesive gel implants, and postoperative malposition occurred in only $1.1 \%$ of cases. Malposition may be more related to errors in implant selection or suboptimal techniques of pocket dissection and pocket dimensions. ${ }^{11}$ Accurate pocket dissection and avoidance of over dissection, along with the use of closed suction drains, are also important factors that will promote device-tissue contact.

Postoperative problems included change of tactile sense of NAC region which was the most frequent and early adverse effect in 11 cases (36.7\% of women), but was temporary in most cases and recovered fully in 9 patient at 6 month follow up. The eight cosmetic augmentation patients complained about postoperative dull pain in their augmented breasts, which gradually subsided in 6 patients within 6months after they were reassured by counselling. Several patients also experienced small seromas ( 5 patients, 16.7\%), hematomas (3 patients, 10\%) and infection in 1 patient at the first week of follow up. All resolved with conservative drainage measures and with antibiotics. Two patients had slight hypertrophic scarring; incidence of visible and/or palpable implant edges at the medial or lateral breast regions occurred in only 2 cases at 6 month. The firmness of the implant can sometimes result in palpable edge. Therefore at the end point of the study only $13.3 \%$ patient had altered nipple sensation and dull aching breast pain; also $13.3 \%$ patient had implant visibility /palpability and hypertrophic scar. The overall implant-related cosmetic complication rate was $13.3 \%$.Sensory changes in the nipple-areola complex and periodical pain in the breasts seem to be common after such surgery.

A short term study by Saify et al ${ }^{14}$ showed Immediate complications comprised delayed wound healing in one case $(2.63 \%)$, one case of haematoma $(2.63 \%)$ and one case of seroma $(2.63 \%)$, and no major late complications occurred during the 1-year follow-up period. The study concluded that most short-term postoperative adverse effects following cosmetic implantation are clinically insignificant and do not require treatment. The inference was similar to our study. According to Fruhstorfer B H ${ }^{11}$ no serious aesthetic complications such as implant malposition or significant capsular contracture were observed. A long-term study done in Copenhagen ${ }^{15}$ reported serious capsular contracture (Baker III and IV) was found in $62 \%$ of patients. Twenty implants $(6 \%)$ in 13 women were recorded as ruptured. Visible implant folds were seen in 19 breasts $(6 \%)$ and breast augmentation had prolonged breast pain, $8.3 \%$ had changes in sensibility, $0.8 \%$ had visible skin wrinkles, and folds were palpated in $1.2 \%$ of women, the majority of the women were troubled by either some $(31 \%)$ or serious $(36 \%)$ breast hardness (capsular contracture). Eighteen percent reported breast pain, in most cases graded as moderate.

None of the patient in our study experienced any vital complications and the pattern of complication occurred were more or less consistent with the short term studies by Saify et $\mathrm{al}^{14}$ and study Fruhstorfer $\mathrm{BH}^{11}$. But long-term studies like the done in Copenhagen ${ }^{15}$ presented serious complications as capsular contracture, implant malposition or rupture probably due to longer follow up period, large population size, and use of long-term cosmetic breast implants dating back to the beginning of the implantation era,. These serious conditions were not seen in the present study. Handel et al have reported that the risk of capsular contracture increases with follow-up time, regardless of type, filler material (textured versus smooth), or surface of implant ${ }^{14}$

Independent review bodies have evaluated the available data on silicone breast implants and concluded that there is no convincing evidence of an association between implants and breast cancer, connective tissue diseases, other rheumatic conditions, neurologic disorders, or effects among offspring. Concerns regarding potential health effects of silicone breast implants have recently shifted from longterm illnesses to postoperative local complications.

\section{Limitations of the present study}

This study is limited by small sample size, not large enough for a representative data and short length of follow-up. The present study has a post-operative follow up period of only 6 months.A longer period of follow up may yield results like the rates for key complications (i.e. contracture, reoperation, explantation, and rupture) as reported in other long-term studies.

\section{Conclusions and recommendations}

Our findings support the short-term safety and effectiveness of the cohesive breast implants.Breast augmentation by 
silicone gel implants are well accepted by the patients, without an increased rate of serious aesthetic complications. They have the potential for providing a natural breast shape, greater degree of safety and can be adopted for general use in cosmetic breast augmentation. However, as longer followup and multicenter studies are still needed to confirm these findings. As silicone gel implant usage continues to grow in Bangladesh, surgeons will have to accommodate more followup and surveillance.

\section{References}

1. Hammond DC and Kuthaila DK .Augmentation Mammaplasty. In: Jeffrey W. Plastic Surgery Secrets plus, 2nd ed. Philadelphia: Mosby Elsevier; 2010; 66:441-446.

2. Maxwell GP, Hartley RW. Breast Augmentation. In: Stephens,JM, Vincent.RH editors.Plastic Surgery, 2nd ed. USA: Saunders Elsevier; 2006; (VI),118 :1-34

3. Lesavoy MA. Breast Augmentation Technique. In: Stephen JM, Vincent RH editors.Plastic Surgery, 2nd ed. USA: Saunders Elsevier; 2006; (VI), 119:35-46.

4. Velasco MG. Refinements in Breast Augmentation: How to obtain aesthetic and natural results.In:M.Eisenmann-Klein, C.Neuhann-Lorenz editors. Innovations in Plastic and Aesthetic Surgery. Heidelberg: Springer-Verlag, 2008; 47:385-391.

5. Bengtson BP, Natta BWV, Murphy DK, Slicton A, Maxwell GP. Style 410 Highly Cohesive Silicone Breast. Implant Core Study Results at 3 Years. Plast Reconstr Surg. 2007; 120(Suppl 1): 405-485.

6. Steven WG, Harrington J, Alizadeh K, Berger L, Broadway D, Hester TR, Kress D et al. Five-year follow-up data from the U.S. clinical trial for Sientra's U.S. Food and Drug Administration-approved Silimed brand round and shaped implants with high-strength silicone gel. Plast Reconstr Surg. 2012 Nov; 130(5): 973-981.

7. Serra-Renom J, Garrido MF, Yoon T. Augmentation mammaplasty with anatomic soft, cohesive silicone implant using the transaxillary approach at a subfascial level with endoscopic assistance. Plast Reconstr Surg. 2005; 116(2): 640-645.

8. Gore SM and Lamberty GH. PERTHESE implant-identical cohesive-gel sizers in breast augmentation: a prospective report on 200 consecutive cases and implications for treatment of breast asymmetry. Aesthet Surg J. 2012; 32(3): 310-318.

9. Spear SL, Murphy DK, Slicton A Walter PS. Inamed silicone breast implant core study results at 6 years. Plast Reconstr Surg, 2007; 120(Suppl 1): 85-165.

10. Cheng MH, Huang JJ. Augmentation mammaplasty in asian women. Semin Plast Surg. 2009 Feb; 23(1):48-54

11. Frutistorfer BH, Hodgson ELB, Malata CM. Early experience with an anatomical soft cohesive silicone gel prosthesis in cosmetic and reconstructive breast implant surgery. Ann Plast Surg. 2004 December; 53(6): 536-542.

12. Psillakis JM, Facehina PH, Kharmandayan P, Trillo L, Canzi WC, Aguiar HR. Review of 1,447 Breast Augmentation Patients Using PERTHESE Silicone Implants. Aesthet Plast Surg. 2010 Feb; 34(1): 11-15.

13. Kulmala I, McLaughlin JK, Pakkanen M, Lassila K, Hölmich LR, Lipworth L, Boice JD Jr, Raitanen J, Luoto R. Local complications after cosmetic breast implant surgery in Finland. Ann Plast Surg. 2004 Nov; 53(5): 413-419

14. Seify H, Sullivan K, Hester TR. Preliminary (3 years) experience with smooth wall silicone gel implants for primary breast augmentation Ann Plast Surg. 2005 Mar; 54(3): 231235 .

15. .Hölmich LR, Breiting VB, Fryzek JP, Brandt B, Wolthers MS, Kjøller K, McLaughlin JK, Friis S. Long-term cosmetic outcome after breast implantation. Ann Plast Surg. Dec 2007; 59:597-604.

16. Hunt J, Salomon J. Augmentation Mammoplasty. Selected Reading in Plastic Surgery. 2002; 9; 28L 1-35. 